\title{
THE FUKUSHIMA DAIICHI NPP ACCIDENT, ITS AFTER EFFECTS AND THE LESSONS LEARNT FROM IT
}

\author{
MD. AKHLAK BIN AZIZ*, MD. FAZLUL HUQ ${ }^{1}$, ZAHID HASAN MAHMOOD², \\ KHORSHED AHMAD KABIR ${ }^{1}$
}

The University of Manchester, Department of Nuclear Science and Technology School of Physics and Astronomy, Manchester M13 9PL, UK

\begin{abstract}
A tsunami induced by an earthquake of magnitude nine hit the Fukushima Daiichi NPP on $11^{\text {th }}$ March, 2011. A seawall of only $10 \mathrm{~m}$ high above sea level against tsunami waves of $15 \mathrm{~m}$, led to a series of catastrophic events like inundation of the backup diesel generators exceptionally located at the basement, hydrogen explosions at three units etc. Immediate evacuation and efficient management ensured negligible harmful effects due to radiation exposure. By 2012, 160,000 people were evacuated. Government gave land and housing to evacuees and an additional USD \$1030 per month for psychological suffering. But evacuees were not allowed to return to regions with radiation of 20-50 $\mathrm{mSv} / \mathrm{y}$ despite IAEA effective dose limit for one year being $50 \mathrm{mSv}$. Moreover, dose limit for clean up workers were also set at $250 \mathrm{mSv}$ compared to international allowable limit of $500 \mathrm{mSv}$. Post accidents efforts taken by the government were praiseworthy but a less conservative limit to allow return of evacuees could have saved a lot more people.
\end{abstract}

Key words: Fukushima daiichi nuclear power station (FDNPS), Radiation

\section{INTRODUCTION}

The accident at the Fukushima Daiichi Nuclear Power Station (FDNPS) on $11^{\text {th }}$ March 2011 was triggered by an earthquake of magnitude 9.0 Richter scale followed by a Tsunami. The accident destroyed the cooling system of FDNPS and led to several explosions from four units at the station (Butler 2011). Hydrogen explosions at three units of the FDNPS severely damaged the respective buildings. The accident caused month-long radioactive discharge contaminating the air, seawater, soil etc. (Chino et al. 2012). The government and
Tokyo Electric Power Company (TEPCO) took several initiatives to minimise the harmful effects of ionizing nuclear radiations on the people and environment. Among many steps some are: they had gradually evacuated people with increasing radius from the FDNPS, deployed rescue robots for cleaning debris and surveillance operations (Nagatani et al. 2013), utilized heavy machines donated by USA and imported from Sweden for reconnaissance inside buildings etc. (Kawatsuma et al. 2012).

\footnotetext{
* Corresponding author: < akhlak69@gmail.com>.

1 Department of Nuclear Engineering, University of Dhaka, Dhaka-1000, Bangladesh.

2 Department of Electrical and Electronic Engineering, University of Dhaka, Dhaka-1000, Bangladesh.
} 
In this paper the accident, causes behind the accident, actions taken by the government, radiation exposure, evacuation criteria and the return of evacuees etc. have been discussed. Based on the discussions, suggestions are made on what could have been done to avoid the disaster and what further actions can be taken, with the aim of avoiding such catastrophe while commissioning NPP and to prepare for emergency situations.

\section{OVERVIEW OF THE ACCIDENT AT THE FUKUSHIMA DAIICHI NUCLEAR POWER STATION (FDNPS)}

On Friday $11^{\text {th }}$ of March, 2011, 14:46 Japan Standard Time (JST), an earthquake of magnitude 9.0 in the Richter scale centred $130 \mathrm{~km}$ off the coast of Sendai in Miyagi prefecture of Japan, struck regions of Japan including four nuclear power stations of Tokyo Electric Power Company (TEPCO) that had eleven reactors on load with a capacity of 9377 MWe (World Nuclear Association 2015a). Reactors were automatically shut down and proved robust seismically and further investigation verified that the earthquake did no damage. But the 15 metre high Tsunami which followed forty-nine minutes later, triggered by the earthquake, was catastrophic for the Fukushima Daiichi Nuclear Power Station (FDNPS) (capacity: $4.7 \mathrm{GWe}$ ) located in the Fukushima prefecture of the Tohoku region, $230 \mathrm{~km}$ north-east of Tokyo.

FDNPS's operating units 1-3 were shutdown by the seismic activity as designed and the units 4-6 were already shutdown due to maintenance and refuelling (UNSCEAR 2013). The earthquake damaged all six external power sources and as a result the Emergency Diesel Generators (EDG) located in the basement of the turbine buildings got activated.

At 15:35 JST a Tsunami with amplitude of 23 metres at point of origin $180 \mathrm{~km}$ from Fukushima struck FDNPS, followed by another Tsunami eight minutes later. At FDNPS a $15 \mathrm{~m}$ wave, above the $6 \mathrm{~m}$ sea wall (10m above sea level), inundated the plant area. The Tsunami damaged twelve of thirteen EDGs, the heat exchangers used for dumping reactor waste heat and decay heat to the sea, seawater pumps located $4 \mathrm{~m}$ above sea level, electrical wiring system, electrical switchgears, batteries and other heat removal systems. The 125 -Volt DC batteries to be used as backups for units 1 and 2 were flooded and failed and unit 3's battery lasted 30 hours. The only active generators were serving units 5 and 6.

There was a station blackout including deactivation of the monitoring equipment and control functions in the central control room. Roads, houses etc. were also damaged making outside access extremely difficult (World Nuclear Association 2015a). Table 1 lists the chronology of key events at FDNPS (National Research Council 2014).

Unit 1: Water level dropped to the top of fuel, fuel temperature rose to $2800^{\circ} \mathrm{C}$ and caused the fuel to melt and drop to the bottom of the reactor pressure vessel (RPV) at 7 a.m. of $12^{\text {th }}$ March. Containment was vented by $2.30 \mathrm{pm}$ but due to insufficient power it back flowed. Hydrogen produced exothermically by oxidation of the zirconium cladding in the presence of steam and air mixture got ignited causing a hydrogen explosion blowing off roof and cladding. 
Table 1. Chronology of key events at FDNPS

\begin{tabular}{ll}
\hline & \\
\hline $14: 46$ & Great East Japan Earthquake \\
$14: 47$ & Unit 1-3 reactors automatically shut down \\
$14: 48$ & Offsite AC power is lost; onsite emergency diesel generators automatically start up to \\
& provide AC power \\
$15: 27$ & First tsunami wave arrives at wave height meter \\
$14: 37$ & Second tsunami wave inundates parts of plant \\
$15: 41$ & Loss of all plant power \\
$16: 36$ & Loss of emergency core cooling system water injection sources \\
$19: 03$ & Japanese government declares a nuclear emergency \\
$20: 50$ & Fukushima prefecture governor orders residents within a 2-km radius of the plant to evacuate \\
$21: 23$ & Japanese government orders evacuation radius to $3 \mathrm{~km}$ \\
\hline & \\
\hline $5: 44$ & Japanese government increases evacuation radius to $10 \mathrm{~km}$ \\
$15: 36$ & Hydrogen explosion occurs in Unit 1 reactor building \\
$18: 25$ & Japanese government increases evacuation radius to $20 \mathrm{~km}$ \\
\hline
\end{tabular}

(World Nuclear Association 2015a and Cooling in the following months from UNSCEAR 2013).

Unit 2: Pressure vented on $13^{\text {th }}$ and $15^{\text {th }}$ and opening of blowout panel at the top helped avoid hydrogen explosion. A leak on primary containment vessel on $15^{\text {th }}$ caused major radioactive release from the site (World Nuclear Association 2015a).

Unit 3: Failure of water injection system caused fuel to melt and fall on the bottom of RPV. To release RPV pressure, successful venting was done on $13^{\text {th }}$ March and when repeated on $14^{\text {th, }}$ events at unit1 were repeated causing hydrogen explosion and a lot of debris (World Nuclear Association 2015a).

Unit 4: Hydrogen of unit 3 reached unit 4 by backflow through shared ducts causing another explosion at 6 a.m. $15^{\text {th }}$ March destroying the top of the building and further demolishing structure of unit 3 (World Nuclear Association 2015a). external sources kept temperature and pressure of RPV below $100^{\circ} \mathrm{C}$ and 1 bar respectively. Finally TEPCO declared cold shutdown on $16^{\text {th }}$ of December 2011 (World Nuclear Association 2015a).

\section{ACTIONS TAKEN BY TOKYO ELECTRIC POWER COMPANY (TEPCO) AND THE GOVERNMENT}

The Director-General of the Nuclear Emergency Response Headquarters (NERHQ) ordered at 21:23 JST to increase the evacuation radius to $3 \mathrm{~km}$. At 5:44 JST the evacuation zone was extended to $10 \mathrm{~km}$ and on the same day at $1825 \mathrm{JST}$ it was expanded to $20 \mathrm{~km}$, covering a total area of $600 \mathrm{~km}^{2}$ (UNSCEAR 2013). The evacuees under 40 years of age leaving the $20 \mathrm{~km}$ radius were advocated by the Nuclear Safety Commission to ingest stable iodine as a precautionary measure against ingesting radioactive iodine via milk etc. Pills and syrups for children and elderly people were 
also taken to the evacuation centers as precautions. Total 160,000 people were evacuated from their homes and only limited return were allowed in 2012 (World Nuclear Association 2015a). Prompt evacuation and a very conservative exposure limit ensured that no one received harmful level of radiation. According to the confirmation in 2013 by United Nations Committee on the Effects of Atomic Radiation, radiation will never have any measurable effect on the population of the Fukushima prefecture as no one through environment or food will be exposed to more than $10 \mathrm{mSv}$ in their entire lifetime and $10 \mathrm{mSv}$ is only one-tenth of which health effects become more pronounced. Health deterioration was due to anxiety, stress, tension and relocation. The 761 deaths were mostly of elderly people ( $90 \%$ people aged more than 66 ) (World Nuclear Association 2015b) all of whom had psychological trauma for being uprooted from their homes by forced evacuation.

To ensure that the radioactive release to the atmosphere remains immobilized, TEPCO sprayed dust-suppressing polymer resin around the plant. Also, to reduce ambient radiation levels TEPCO removed significant amount of debris using remote controlled equipment. Shipments of rice to markets were only allowed after thorough testing. Tests showed highest level were only one quarter of the allowable limit of $500 \mathrm{~Bq} / \mathrm{kg}$. To limit airborne radioactive releases $54 \mathrm{~m}$ high covers with ventilation system for measuring radioactivity were progressively built over the affected units starting with unit 1 (World Nuclear Association 2015a).

Even though the radioactivity could not be detected in seawater beyond plant harbour, a slit fence had been placed to prevent ground water that gets contaminated by interacting with water in the basements of the FDNPS buildings from reaching the open sea. Since radioactive material was found in certain species of fish, food from affected areas were strictly monitored (World Nuclear Association 2015a, World Nuclear Association 2015c). The monitoring of food and drinking water by the Japanese and prefectural governments began as early as $16^{\text {th }}$ March 2011. Foods like milk, vegetables, grains, meat, fish etc. that had radioactive material higher than the provisional regulation values declared on $17^{\text {th }}$ March 2011 by the Ministry of Health, Labour and Welfare, were forbidden from distribution and consumption on 21 March and 23 March 2011 respectively (UNSCEAR 2013).

The core materials of the destroyed reactors contaminated water used for cooling. A large treatment plant was built to treat the water and a large storage capacity was built to hold the treated water. Also nitrogen was constantly injected into the reactor cores so that an inert atmosphere is maintained (World Nuclear Association 2015d).

From 12 $2^{\text {th }}$ March 2011 staffs of NERHQ very promptly started surveying the skin and clothing of the residents for contamination using Geiger-Muller survey meters (UNSCEAR 2013). By the end of May 2011, 195345 residents were monitored and none of them required decontamination. Staffs of NERHQ also conducted thyroid gland surveys of 1080 children aged between 0 and 15 years living in Kawamata town, Iitate village and Iwaki city. These surveys from $26^{\text {th }}$ and $30^{\text {th }}$ March that used handheld 
sodium iodide monitors concluded that none of the children exceeded the normal screening level of absorbed dose from internal exposure. The normal level of ${ }^{131} \mathrm{I}$ is $100 \mathrm{mGy}$ for a 1-year-old infant (UNSCEAR 2013).

The government is helping the municipalities with the decontamination process and infrastructure repairs so that people can soon return to their homes. The government is also ready to buy the houses and lands of the evacuees in the affected areas (World Nuclear Association 2015a).

Japanese government pays the evacuees for land, housing and an additional JPY 100,000 $(\$ 1,030)$ per month as compensation for psychological suffering. By October 2013 government paid $\$ 30$ billion to eighty-four thousand nuclear accident victims in contrast to $\$ 20$ billion to 300,000 tsunami victims (World Nuclear Association 2015a).

Since the accident a large number of important data related to the dose, the government and TEPCO produced rates. This information helped in making crucial decisions (IAEA 2013) for the people and workers.

TEPCO compensated for the lack of initial number of personal dosimeters and other essential equipment at the site so that the workers were prevented from external and internal exposure to radiation. On November 2011, initial emergency dose limit of 250 $\mathrm{mSv}$ was reduced to $100 \mathrm{mSv}$ for new workers. Potassium iodide tablets were distributed among FDNPS workers who were under 40 years of age and who requested it. Special tight fitted full-face respirators were given to the workers to minimize the inhalation of radioactive particles and gases (World Nuclear Association 2015a). Physical barriers and working time were implemented in designated areas. Special coordination centers were established for special needs. To minimize contamination of body surfaces they were also given protective overalls, gloves, safety shoes, cotton hats and helmets (World Nuclear Association 2015a).

\section{RADIATION LEVELS}

In May 2012 estimates published by TEPCO showed a total of $1020 \mathrm{PBq}$ were released to the atmosphere from 12-31 March 2011 of which $20 \%$ came from Unit 1, 40\% from Unit 2 (peak on 15 March), and 40\% from Unit 3 (peak on 16 March). From 26 March to 30 September 2011 releases to the ocean were about $11 \mathrm{PBq}$ iodine-13, 3.5 PBq Cs-134, 3.6 PBq Cs-137, total 18.1 PBq (or 169 PBq I-131 eq) (World Nuclear Association 2015a). Among the many fission products released, the main radionuclides were volatile iodine131 with a half-life of 8 days, soluble caesium-137 (can be taken into the body but does not concentrate in any organ) with a halflife of 30 years (biological half-life 70 days) and caesium-134 with a half-life of 2 years. Cs-137, a strong gamma emitter, can easily be carried in plume, can contaminate and stays long when it lands. Following hydrogen explosions on $12^{\text {th }}, 13^{\text {th }}$ and $15^{\text {th }}$ March, radioactive iodine and caesium were detected in the vicinity of the FDNPS. However, compared to caesium, effects of $\mathrm{Pu}$ and $\mathrm{U}$ in the vicinity of FDNPS were insignificant (Sakaguchi et al. 2012). More than 100 seawater samples were collected from the North Pacific Ocean in April and May 2011. 
All of them contained Cs-134 and most of them contained Cs-134. Activity of Cs-137 ranged from 1 to $1000 \mathrm{~Bq} \mathrm{~m}^{-3}$ with activity ratios of Cs-134/Cs-137 close to 1 proving that the radiocaesium originated from the FDNPS (Aoyama 2013). Iodine and caesium were also found in soil core samples collected from the Fukushima prefecture. But their migration to soil layers deeper than $5 \mathrm{~cm}$ was limited due to their strong affinity towards humic substances and clay minerals (Tanaka et al. 2012). Cs-137 contaminated soils in large areas of eastern and northeastern Japan, whereas western regions were sheltered by mountain ranges (Yasunari et al. 2011). Only $13 \%$ of $\mathrm{I}-131$ and $22 \%$ of Cs-137 were deposited on land of Japan and the remaining were either deposited in the ocean or transported out (Morino et al. 2011). Most of the Cs-134 (14 out of 15PBq) and Cs-137 were from unit 2 . Ten times more iodine was released from unit 2 than unit 1 , and unit 3 released half of that from unit 1 (World Nuclear Association 2015a).

\section{JUSTIFIABLE LEVELS OF DOSE FOR FIRST-RESPONSE WORKERS}

Checks for both external and internal doses using whole-body counters showed that only 167 workers had received doses over 100 $\mathrm{mSv}$. Of them 135 had received 100 to 150 $\mathrm{mSv}$, twenty three 150-200 mSv, three 200$250 \mathrm{mSv}$ and six from 309 to $678 \mathrm{mSv}$. Even the highest doses received by the units 3 and 4 control room operators who were not wearing breathing apparatus, were not enough to cause radiation sickness and were received only in the first two days due to inhaling iodine-131 fumes. Workers now wear personal monitors, breathing apparatus and protective clothing that protect against alpha and beta radiation, and are under continuous check-ups (World Nuclear Association 2015a).

The maximum allowable short term dose limit for Fukushima accident clean up workers was set at $250 \mathrm{mSv}$ by Nuclear and Industry Safety Agency (NISA) which is

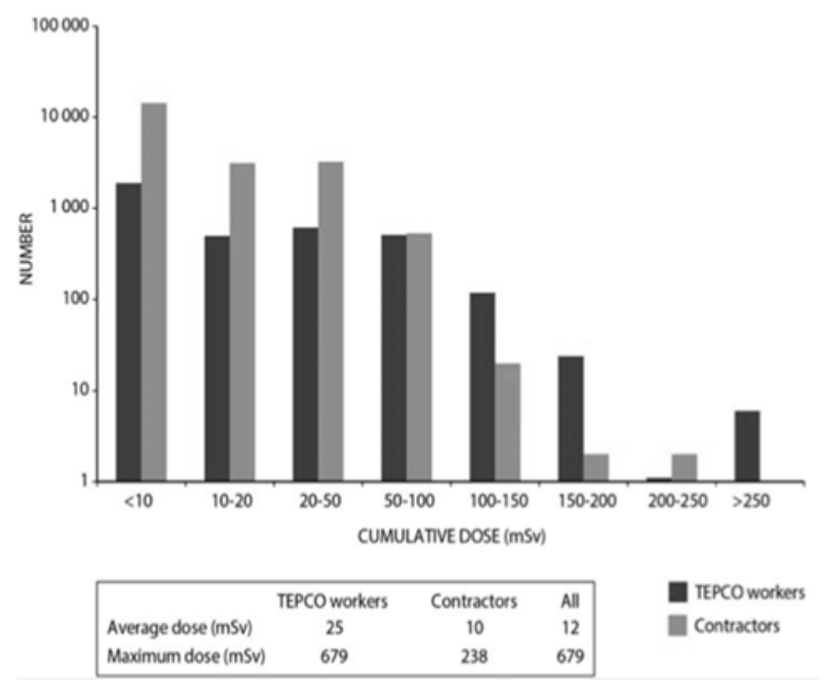

Fig. 1. Doses received by TEPCO workers and contractors. (UNSCEAR 2013) 
only half and very conservative when compared to the $500 \mathrm{mSv}$ international allowable short term dose for emergency workers taking life saving actions (World Nuclear Association 2015a). Fig. 1 shows doses received by TEPCO workers and contractors. (UNSCEAR 2013).

\section{REMEDIATION}

Government is implementing the remediation work in Special Decontamination Areas of eleven municipalities that are within $20 \mathrm{~km}$ of FDNPS, having dose rate mostly greater than $20 \mathrm{mSv} /$ year. The Special Decontamination Area is further classified into the following three categories:

Green: Dose level below $20 \mathrm{mSv}$ and above $1 \mathrm{mSv}$

Yellow: Dose level between $20 \mathrm{mSv}$ and 50 $\mathrm{mSv}$

Red: Dose level over $50 \mathrm{mSv}$

With the help of government funding and technical support, another hundred municipalities were performing decontamination in areas outside $20 \mathrm{~km}$ of
FDNPS having dose rate 1-20 mSv/year, known as Intensive Decontamination Survey Areas (IDSA). The contractors of the municipalities carry out different pilot tests on procedures to decide which one to implement. The ministry of environment had formulated a set of guidelines in December 2011 on decontamination called 'Decontamination Guidelines'. The guidelines presented the methods of investigating the status of environment in the affected areas and the techniques of decontamination that can be applied (World Nuclear Association 2015a).

According to a primary report of a sixteen member IAEA mission, the decontamination efforts by the authorities were praiseworthy but the targets set were unrealistic. IAEA found that excellent progress had been made in the remediation of the affected farmland of IDSA (IAEA 2013). Extensive monitoring proved that the foodstuffs produced had well below reference level of permissible radioactivity. The radiation dose of less than $20 \mathrm{mSv} /$ year in IDSA complies with the international standards set by relevant

Table 2. Decontamination technique

\begin{tabular}{|l|l|}
\hline \multicolumn{1}{|c|}{ Decontaminated item } & \multicolumn{1}{c|}{ Decontamination technique used } \\
\hline Eaves and roof gutters & Wiping and high-pressure washing after removing deposited material \\
\hline Storm water catch basins & High-pressure washing after removing deposited material \\
\hline Street gutters & High-pressure washing after removing deposited material \\
\hline Roofs & Wiping, washing, high-pressure washing \\
\hline Outer walls & Wiping, washing, high-pressure washing \\
\hline Garden and other grounds & $\begin{array}{l}\text { Mowing grass, collection of clippings, pruning surface soil removal, } \\
\text { replacing turf, ploughing }\end{array}$ \\
\hline $\begin{array}{l}\text { Parking lots and other } \\
\text { paved surfaces }\end{array}$ & Washing, high-pressure washing, surface removal \\
\hline School athletic grounds etc. & Surface dirt removal \\
\hline Roads & Washing, high-pressure washing, shaving-off \\
\hline
\end{tabular}


Fig. 2. Furnishes the implementation techniques as indicted in Table 2.

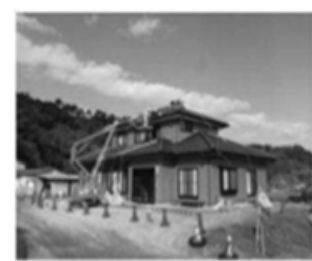

Wiping off rooftop and walls

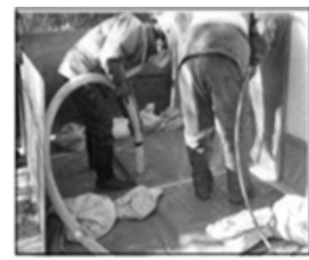

High pressure water cleaning of Mowing and removal of sludge paved road

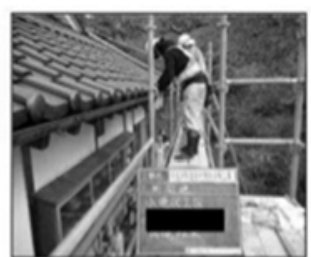

Wiping off a gutter

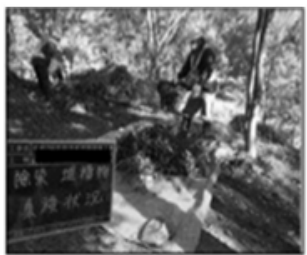

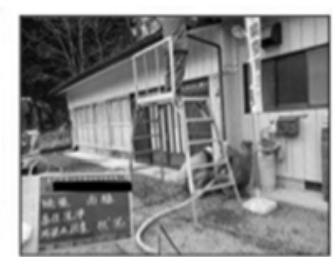

High pressure water cleaning of a drain pipe

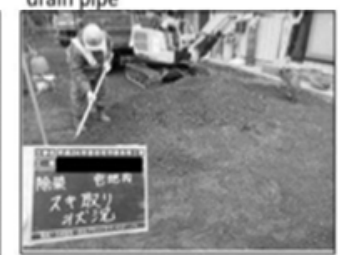

Removal of crushed stones and topsoil, and cover with clean soil

Fig. 2. Implementation of techniques shown in the table above (IAEA 2013).

international organizations such as ICRP, IAEA, UNSCEAR, and WHO etc. As a result people must return and the government must make the stakeholders aware that it is safe. There is potential to produce food safely in those regions and the goal of achieving $1 \mathrm{mSv} /$ year is unjustified and not required in the short term.

A thorough monitoring programme of radioactivity concentrations in water, sediment and suspended sediment, as well as extensive food monitoring of freshwater fish (wild and cultivated), is going on (IAEA 2013). Some decontamination techniques used for different items are shown in Table 2 and Fig. 2.

\section{EXCLUSION ZONE AND RETURN OF EVACUEES}

At 7:03 pm Friday $11^{\text {th }}$ March a nuclear emergency was declared and at 8:50 pm an evacuation for people within $2 \mathrm{~km}$ radius was ordered. By the evening of $12^{\text {th }}$ March it was extended to a $20 \mathrm{~km}$ radius. $20 \mathrm{mSv} /$ year criterion was applied to determine return of evacuees in areas having radius greater than $20 \mathrm{~km}$. From the contaminated area of 20-40 $\mathrm{km}$ northwest of the plant, 15,000 people were displaced in mid-May taking the total to 100,000. From April 2012, the Ministry of Economy, Trade and Industry (METI) allowed restricted return to regions within 20 $\mathrm{km}$ radius around the plant and in portions of the Minami Soma city extending more than 20 $\mathrm{km}$ north (World Nuclear Association 2015a and World Nuclear Association 2015b). These regions were further classified into:

I. Regions with radiation level less than 20 $\mathrm{mSv} /$ year were taken off from evacuation.

II. Regions with 20-50 mSv/year were allowed entrance without precautionary measures and only for specific purposes. Decontamination and remediation were going on in these regions and would be completed by 2017 . 
III. Regions with radiation levels greater than $50 \mathrm{mSv} /$ year are still restricted to entry except for some special purposes. These restricted areas lie within the 20 $\mathrm{km}$ radius evacuation zone and the radiation levels are not expected to fall below 20mSv/year before March 2016.

In July 2012, METI added Litate village to the evacuation zone. It is $28-45 \mathrm{~km}$ northwest of the Daiichi plant and adjacent to the northern part of Minami Soma city. An urgent field survey carried out on 28 and 29 March 2011 showed that volatile radionuclides like iodine and caesium were the main components of radioactive contamination. Also, an exposure rate of more than twenty micro Sieverts per hour was observed only in the southern part of the lilate village (Tetsuji et al. 2012). Now, except $10 \mathrm{sqkm}$ area of lilate and some part of Minami Soma city joining lilate within the 20 $\mathrm{km}$ radius of Daiichi plant that remain fully evacuated, lilates's citizens are allowed to return without protective gear but cannot stay overnight. By August 2012, people of Naraha town in the south and parts of Okuma-machi in the southwest of the plant were allowed to return in the same way as the citizens of lilate, making more than half of the originally evacuated area accessible. After August 2013, Fu taba, within $20 \mathrm{~km}$ radius of the plant, was the only municipality to remain closed to the return of the evacuees. Infrastructure destroyed by the Tsunami was another major factor that limited the return of the evacuees. Most of the 72800 people who used to live in the towns and villages of Futaba were economically reliant on the plant and were thus mostly affected (World Nuclear Association 2015a). Nuclear regulatory authority (NRA) continuously measure individual external exposure doses for Fukushima prefecture residents as part of the study on 'Safety and Security Measures towards Evacuees Returning Home (IAEA 2013).

\section{STAKEHOLDERS INVOLVEMENT AND THEIR POSITION}

IAEA showed demonstrable evidence that communication and engagement processes have been adopted by the provincial governments to get local people more involved with the issues (IAEA 2013). These initiatives encouraged people and they regained their trust. The 'decontamination outreaching plaza' and its outreaching activities are also pushing forward the stakeholder engagement process (IAEA 2013). The prefectural government conducted surveys that showed $70 \%$ had relatives suffering physical and mental health problems, $48.9 \%$ of households had family members living in two or more locations and $58.6 \%$ people had relatives who once lived together but are now scattered in three or more places (The Guardian 2014). Although people are worried about health implications of children, they are suffering more for living away from family and home and for regular shifting than for the accident itself. Government's conservative approach is not solving the problem very soon.

\section{ECONOMIC EFFECTS AND POLITICAL RESPONSE}

FDNPS disaster led to the closure of all the Japan's 48 nuclear power stations, which produced $30 \%$ of its electricity (BBC NEWS 2014). Instead of increasing the value to $40 \%$ by 2017 as projected before 2011, it went to 
zero. The import cost of alternatives to nuclear energy is $\$ 40$ billion per year (World Nuclear Association 2015a) and had cost a staggering \$204 billion from 2011 to end of 2013 (Mail Online 2014). Impact of FDNPS accident and moving away from nuclear energy is enormous and eating away a meaty proportion of its GDP.

Naoto Kan, Prime Minister of Japan during the FDNPS disaster, was anti nuclear and pledged to end nuclear power by 2040 (Mail Online 2014). But the good part is that the current government of Shinzo Abe is pro nuclear. Shinzo Abe is very popular as he is the one who pulled Japan out of recession. He was re-elected in 2012 after his successors failed to even last one full term. Shinzo Abe's lobbying led the way to restart Sendai reactor last November, 2016 (BBC NEWS 2014). Japan nuclear industry is looking forward to starting a new era under the leadership of Shinzo Abe.

\section{DISCUSSION}

In Japan, earthquakes of magnitude 7.7 richter scale induced Tsunamis in 1983 and 1993 with maximum heights at origin of $14.5 \mathrm{~m}$ and $31 \mathrm{~m}$ respectively. In June 1896 an earthquake of magnitude 8.3 created a massive Tsunami of $38 \mathrm{~m}$ in the Tohoku region killing 27,000 people. Leading up to the 2011 disaster, scientific studies warned about the possibility of a large earthquake and a Tsunami of $15.7 \mathrm{~m}$ at the Daiichi plant. Although the sea wall at the site was only $10 \mathrm{~m}$, the massive Tsunamis in the past and the warnings from the scientific society had not led to any major actions by the plant operator, TEPCO or government regulators. Had the warnings been taken into account more seriously, the accident could have been avoided. Moreover, the EDGs were located at the basement of the FDNPS. Knowing that flash floods and Tsunamis can easily inundate the basement, placing the EDGs at the basement was not a good option. Effects of Tsunami had been avoided at other nuclear power stations in Japan like the one in Daiini due to its high sea wall and EDG being located at higher levels.

The actions taken by the government and TEPCO following the accident are commendable and can be followed by any country in order to tackle disasters of large scale. But the radiation dose limit of 250 $\mathrm{mSv}$ set for the first response workers is only half of international standard. Similarly, dose limits set for return of evacuees and resuming normal operation is unnecessarily conservative. All 1000 deaths reported were for maintaining evacuation and due to psychological trauma faced, in contrast to very little risk involved had early return been allowed (World Nuclear Association 2015a). Maintaining conservative evacuation is thus only increasing the suffering of people by keeping them away from their homes and families.

\section{CONCLUSION}

Design issues like the height of the seawall and the location of the emergency diesel generators played a major role in FDNPS accident. Countries that are vulnerable to earthquake and floods like Japan can take lessons learnt from FDNPS accident. Such lessons are: sea walls must be strong and high enough to prevent Tsunami, backup power systems must be maintained in such a way so that it will not be affected by any 
kind of disaster like cyclone, flood, earthquake etc.

Apart from the conservative dose limits used to take decisions at various points, actions taken by the Japanese authorities are praiseworthy. After effects including the health physics related issues th at are similar to Three Mile Island accident (Bevelacqua 2011) were well managed, and can be emulated for emergency preparedness of workforce at any NPP.

\section{REFERENCES}

Aoyama, M., D. Tsumune and Y. Hamajima. 2013. Distribution of ${ }^{137} \mathrm{Cs}$ and ${ }^{134} \mathrm{Cs}$ in the North Pacific Ocean: impacts of the TEPCO Fukushima-Daiichi NPP accident. Journal of Radioanalytical and Nuclear Chemistry. 296(1): 535-539.

BBC NEWS, 2014. Japan governor approves Sendai reactor restart. Available at: < http://www.bbc.co.uk/news/world-asia29947564> [Accessed 14 June, 2015].

Bevelacqua, J. 2011. Applicability of health physics lessons learned from the Three Mile Island Unit 2 accident to the Fukushima Daiichi accident. Journal of Environmental Radioactivity, Vol. 105, pp. 6-10.

Butler, D. 2011. Radioactivity spreads in Japan. Nature 471 : 555-556.

Chino, M., H. Nakayama, H. Nagai, H. Terada, G. Katata and H. Yamazawa. 2012. Preliminary estimation of release amounts of ${ }^{131} \mathrm{I}$ and ${ }^{137} \mathrm{Cs}$ accidentally discharged from the Fukushima Daiichi Nuclear Power Plant into the atmosphere. Journal of Nuclear Science and Technology, 48(7): 1129-1134.

International Atomic Energy Agency (IAEA). 2013. Final Report The Follow-up IAEA International Mission on Remediation of Large Contaminated Areas Off-Site the Fukushima Daiichi Nuclear Power Plant.

Kawatsuma, S., M. Fukushima, T. Okada. 2012. Emergency response by robots to Fukushima-Daiichi accident: summary and lessons learnt. Industrial Robot: An International Journal, 39(5): 428-435.
Mail Online. 2014. Three years after Fukushima disaster prompted Japanese vow to abandon nuclear energy, the country plans to reopen power plants... and possibly build MORE. Available at: $<$ http://www.dailymail.co.uk/ news/article-2568430/Three-years-

Fukushima-disaster-prompted-Japanesevow-abandon-nuclear-energy-country-plansreopen-power-plants-possibility-buildMORE.html>[Accessed 19 June, 2015].

Morino, Y., T. Ohara and M. Nishizawa. 2011. Atmospheric behaviour, deposition, and budget of radioactive materials from the Fukushima Daiichi nuclear power plant in March 2011. Geophysical Research Letters, 38(7).

Nagatani, K., S.Kiribayashi, Y. Okada, K. Otake, K. Yoshida, S. Tadokoro, T. Nishimura, T. Yishida, E. Koyanagi, M. Fukushima and S. Kawatsuma. 2013. Emergency response to the nuclear accident at the Fukushima Daiichi Nuclear Power Plants using mobile rescue robots. Journal of Field Robotics, 30(1): 44-63.

National research council. 2014. Lessons learned from the Fukushima nuclear accident for improving safety of U.S. nuclear plants, The national academics press.

Sakaguchi, A., A.Kadokura, P. Steier, K. Tanaka, Y. Takahashi, H. Chiga, A. Matsushima, S. Nakashima and Y. Onda. 2012. Isotopic determination of $\mathrm{U}, \mathrm{Pu}$ and $\mathrm{Cs}$ in environmental waters following the Fukushima Daiichi Nuclear Power Plant accident. Geochemical Journal, 46: 355-360.

Tanaka, K., Y. Takahashi, A. Sakaguhi, M. Umeo, S. Hayakawa, H. Tanida, T. Saito and Y. Kamai. 2012. Vertical profiles of Iodine131 and Cesium-137 in soils in Fukushima prefec T. J.ture related to the Fukushima Daiichi Nuclear Power Station accident. Geochemical journal, 46: 73-76.

Tetsuji, I., E. Satoru, S. Masuro, Q. Shoji, S. Kiyoshi and Y. Masayoshi. 2012. Early radiation survey of Iitate village, which was heavily contaminated by the Fukushima Daiichi accident, conducted on 28 and 29 March 2011. The radiation safety journal Health Physics, 102(6): 680-686. 
The Guardian. 2014. Fukushima nuclear disaster: three years on 120,000 evacuees remain uprooted. [Online] Available at: $<\mathrm{http}: / /$ www.theguardian.com/world/2014/sep/10/fu kushima-nuclear-disaster-japan-three-yearsfamilies-uprooted $>$ [Accessed 13 October, 2015].

UNSCEAR. 2013. Sources effects and risks of ionizing radiation. UNSCEAR 2013 Report to the general assembly with scientific annexes (2013).

World Nuclear Association (WNA), Fukushima Accident. 2015a. Available at: $<$ http://www. world-nuclear.org/info/Safety-andSecurity/Safety-of-Plants/FukushimaAccident/> [Accessed 5 June, 2015].

World Nuclear Association (WNA). 2015b. Fukushima: Radiation Exposure. Available at: $<$ http://www.world-nuclear. org/info/ Safety-and-Security/Safety-of-Plants/ Appendices/Fukushima--RadiationExposure/ $>$ [Accessed 12 June, 2015].
World Nuclear Association (WNA). 2015c. The Situation at Fukushima. Available at: $<$ http://www.world-nuclear.org/Features/ Fukushima/Situation-at-Fukushima/> [Accessed 4 June, 2015].

World Nuclear Association (WNA). 2015d. Fukushima Daiichi Reactor Recovery measures in Detail. Available at: $<$ http:// www.world-nuclear.org/info/Safety-andSecurity/Safety-of-Plants/Appendices/ Fukushima--Reactor-Recovery-Measures-inDetail/> [Accessed 6 June, 2015].

Yasunari, T.J., A. Stohi, R.S. Hayano, J.F. Burkhart and S.T. Eckhardt. 2011. Cesium137 deposition and contamination of Japanese soils due to the Fukushima nuclear accident. Proceedings of the National Academy of Sciences of the United States of America, 108(49): 19530-19534.

(Received revised manuscript on 15 February, 2018) 